\title{
Fatores condicionantes para a tendência de uso de tecnologias de informação e comunicação (TICs) no ensino superior em Moçambique
}

\author{
Conditioning factors for the trend in the use of information and communication technologies (ICT) \\ in higher education in Mozambique
}

Factores condicionantes en la tendencia de uso de tecnologías de información y comunicación

(TICs) en la educación superior en Mozambique

Recebido: 13/05/2021 | Revisado: 18/05/2021 | Aceito: 25/05/2021 | Publicado: 09/06/2021

\author{
Lainesse Benjamim Samussne \\ ORCID: https://orcid.org/0000-0001-7415-2953 \\ Instituto Superior Politécnico de Manica, Brasil \\ Universidade Federal de Viçosa, Brasil \\ E-mail: manhunhute@gmail.com \\ Suely de Fátima Ramos Silveira \\ ORCID: https://orcid.org/0000-0002-1303-7190 \\ Universidade Federal de Viçosa, Brasil \\ E-mail: sramos@ufv.br \\ Antônio Carlos Brunozi Júnior \\ ORCID: https://orcid.org/0000-0001-9372-6246 \\ Universidade Federal de Viçosa, Brasil \\ E-mail: acbrunozi@yahoo.com.br \\ Denyse Claudette Sebastião Alexandre \\ ORCID: https://orcid.org/0000-0002-5558-0650 \\ Instituto Superior Politécnico de Manica, Moçambique \\ E-mail: denysedette42@gmail.com \\ Anderson Oliveira Reis \\ ORCID: https://orcid.org/0000-0003-2861-5472 \\ Universidade Federal de Juiz de Fora, Brasil \\ E-mail: andersonccoufv@gmail.com.br
}

\begin{abstract}
Resumo
O uso crescente das TICs e a sua capacidade de transformar os processos educacionais tem sido assunto de destaque nas discussões de políticas de educação superior, despertando a atenção para a necessidade de debates acadêmicos que visam entender aspetos ligados a aceitação e uso das TICs nos processos de ensino. O presente estudo, recorre à Teoria Unificada de Aceitação e Uso da Tecnologia (UTAUT), para analisar os fatores que os docentes do ensino superior púbico, percebem como sendo determinantes e que influenciam a tendência de utilização de TICs nas IES em Manica, Moçambique. Para a coleta de dados, foi desenvolvido um questionário online e enviado a 207 docentes das IES públicas da província de Manica, dos quais, 103 responderam. Os dados foram analisados usando a análise fatorial e a regressão logística binominal. Os resultados do estudo indicaram que os docentes percebem como fatores determinantes para a utilização TICS a expectativa de desempenho, as condições facilitadoras e a expectativa de esforço. Estes três fatores contribuem positivamente na tendência de uso das TICs.
\end{abstract}

Palavras-chave: UTAUT; Tecnologias de informação e comunicação; Tecnologia; Ensino superior; Moçambique.

\begin{abstract}
The growing use of ICTs and their ability to transform educational processes has been a prominent issue in higher education policies. Thus, drawing attention to the need for academic debates to understand the acceptance and utilization of ICTs in the teaching process. This study uses the Unified Theory of Acceptance and Use of Technology (UTAUT) to analyze the factors that teachers in public higher education institutions perceive as a determinant in the trend of using ICTs in HEIs in Manica, Mozambique. A web-based survey was developed and submitted to 207 teachers in Manica higher education institutions, and a total of 103 teachers responded to the survey. Factor analysis and binomial logistic regression were used to analyze the data. The study results indicate that the teachers perceive as determining factors for using ICTs: the performance's expectation, the facilitating conditions, and the expected endeavor. These three factors contribute positively to the trend of using the ICTs in Manica HEIs.
\end{abstract}

Keywords: UTAUT; Information and communication technologies; Technology; Higher education; Mozambique. 


\section{Resumen}

El uso creciente de las TICs y su capacidad para transformar los procesos educacionales han sido temas destacados en las discusiones de políticas de educación superior, llamando la atención sobre la necesidad de debates académicos que buscan entender aspectos relacionados con la aceptación y uso de las TICs en los procesos de enseñanza. El presente estudio se sustenta en la Teoría Unificada de Aceptación y Uso de la Tecnología (UTAUT por sus siglas en inglés) para analizar los factores que los docentes de educación superior pública ven como determinantes y que influyen en la tendencia de utilización de TICs en las instituciones de educación superior (IES) en Manica, Mozambique. Para la recolección de los datos, fue realizado un cuestionario online a 207 docentes de las IES públicas de la provincia de Manica, de los cuales, 103 respondieron. Los datos fueron analizados mediante análisis factorial y regresión logística binomial. Los resultados del estudio indicaron que los docentes ven como factores determinantes para la utilización de las TICs la expectativa de desempeño, las condiciones facilitadoras y la expectativa de esfuerzo. Estos tres factores contribuyen positivamente en la tendencia de uso de las TICs.

Palabras clave: UTAUT; Tecnologías de información y comunicación; Tecnología; Educación superior; Mozambique.

\section{Introdução}

Mudanças globais, como no acesso às informações, na agilidade do setor financeiro, nos tratamentos de saúde e nas formas de ensino da educação, a exemplos, têm sido identificadas em virtude dos avanços tecnológicos e comunicacionais, que possibilitam os países e organizações de várias partes do mundo realizarem diversas transações em qualquer região no mesmo instante. No entanto, para se adaptar a tal contexto, as organizações públicas e privadas, a dado nível de exigência, necessitam de alterações no que tange as suas configurações (ou formas de estrutura) para fazer face ao processo de globalização das informações e comunicações ( Correia \& Santos, 2013; Nganga, 2015) .

Nesse ambiente, os países, bem como as diferentes organizações, são levados a adotar as Tecnologias de Informação e Comunicação (TICs) em seus processos de atuação nos cotidianos, objetivando que a comunicação aconteça de forma ideal. Embora ainda exista junto a alguns países, e a organizações públicas e privadas, um certo nível de resistência ou limitações, quanto à necessidade de alterações no que tange as configurações destas instituições ante ao processo de globalização das informações e comunicações.

Segundo Correia e Santos (2013) e Nganga (2015), as TICs estão relacionadas aos procedimentos, métodos e equipamentos utilizados para processar as informações e comunicá-las aos interessados. Elas têm por característica a rapidez do conteúdo da comunicação, por meio da digitalização e da comunicação em redes (Internet), sendo esta a sua mais expressiva forma, com o intuito de captar, transmitir e distribuir as informações, que podem assumir a forma de texto, imagem estática, vídeo ou som.

Rosa (2009) reconhece que a educação é um segmento que está sendo transformado pelas TICs, demonstrando o seu papel nas mudanças sociais, econômicas e na sua capacidade de permitir o rápido acesso à informação e produção do conhecimento. Realça-se o potencial didático-pedagógico das TICs para o processo ensino-aprendizagem no sistema educacional.

As instituições de ensino superior (IES) não estão alheias aos avanços tecnológicos, considerando que elas são responsáveis pelo processo de formação do "homem do amanhã", fazendo com que haja exigências para com as IES, no que tange a substituição dos métodos tradicionais pelas TICs, com o intuito de que elas se adequem da melhor maneira frente a situação atual que o mercado educacional os coloca (Bento \& Prus, 2011).

Garcia, Rabelo, Silva e Amaral, (2012) reforçam a necessidade de os professores modificarem a forma de pensamento no processo de ensino, abandonando o paradigma tradicional, caracterizado pelo distanciamento entre o professor e aluno, reforçando que, para além de uma questão técnica, de capacitar a instituição de ensino com equipamentos tecnológicos, é necessário tornar o docente um profissional crítico, reflexivo e competente para o domínio das novas tecnologias digitais.

Adicionalmente, devido à COVID-19 e seus efeitos dramáticos em todos os países, a necessidade de adesão às TICs 
tornou-se imperativa para as atividades dos setores econômicos e sociais em todas as partes do planeta. Porém, mesmo com o discorrido, há de se apontar que o progresso e a propagação das TIC a nível global, estão claramente vinculados a um desenvolvimento contínuo e acelerado, o que, com o passar do tempo, pode acarretar em mudanças no comportamento das pessoas e, simultaneamente, possibilitar um descompasso entre as gerações de professores e alunos, trazendo consequências para o processo de educação (Garcia et al. (2012). Na maioria dos casos, nem todas as nações estão preparadas ou possuem as mesmas condições para adotar ou implementar TICs.

Diante desse contexto, em que se ressalta um novo caminho da sociedade da ciência da informação e tecnologia no processo das IES, o presente estudo tem a seguinte indagação: Quais fatores influenciam na tendência de uso das TICs por professores do ensino superior público na província de Manica, em Moçambique? Para responder à esta questão o objetivo geral da pesquisa foi analisar, na percepção de professores do ensino superior, os fatores que influenciam a tendência de utilização de tecnologias de informação e comunicação em Manica, Moçambique.

$\mathrm{Na}$ literatura sobre o tema verifica-se que a utilização da tecnologia é influenciada por diversos fatores, e em consequência, ela nem sempre é bem recebida. Conforme Nganga (2015), esses fatores variam de acordo com a perspectiva demográfica do indivíduo (idade, sexo, nível de instrução), bem como àqueles relacionados à utilidade, atitude e influência social.

Para sua consecução, este estudo fundamentou-se na teoria Teoria Unificada de Aceitação e Uso da Tecnologia (Unified Theory of Acceptance and Use of Thechology-UTAUT) desenvolvida por Venkatesh, Morris, Davis, e Davis (2003). Segundo Castro (2014), essa teoria considera quatro fatores determinantes e quatro condições moderadoras da aceitação e intenção de uso da Tecnologia da Informação pelas pessoas das organizações. Os fatores determinantes influem diretamente na intenção e aceitação de uso, sendo eles: a expectativa de performance, a expectativa de esforço para o uso, a influência social, e as condições facilitadas. Já as condições moderadoras influenciam indiretamente a intenção e aceitação de uso são: o gênero, a idade, a experiência e a voluntariedade do uso por parte do usuário.

Por sua vez, vale mencionar que a escolha de Moçambique como local de estudo fundamenta-se por ser um país em processo de desenvolvimento, cujas infraestruturas foram devastadas pela guerra civil. Como forma de reatar o desenvolvimento, foram realizadas diversas reformas, dentre elas a introdução da política nacional de informática no ano 2000, tendo como suas principais parceiras as IES públicas, que desempenham um papel crucial na implementação da política nacional das TICs. As Instituições de Ensino Superior foram chamadas a procurar soluções que permitam expandir a utilização das TICs visando a obtenção de benefícios nos processos produtivos, bem como melhoramentos dos processos de ensino e aprendizagem, e pesquisa. Passados cerca de 20 anos após aprovação da referida política em Moçambique, torna-se relevante estudar os desafios de utilização das TIC nos processos acadêmicos das instituições que foram parceiras na implementação da política.

As contribuições aqui percebidas estão relacionadas ao fato de apoiar aos gestores das IES de Manica na identificação dos fatores que mais influenciam para tendência de uso das TICs e potencializá-los como forma de melhorar a gestão de todo o processo de ensino e aprendizagem. Achados desta pesquisa indicaram uma menor tendência de uso das TICs pelos participantes da amostra, estando relacionada com a existência de desafios em termos de criação de infraestruturas básicas para que os recursos funcionem em plenitude. A expectativa de desempenho, condições facilitadoras a expectativa de esforço são os fatores determinantes do modelo UTAUT que tiveram influência positiva na tendência de uso das TIC entre os participantes da amostra.

O artigo foi estruturado em cinco seções, a partir da Introdução, apresenta-se, na segunda, uma breve revisão de literatura destacando a Tecnologia de Informação e Comunicação na Educação e em Moçambique, acrescentando-se, também, a Teoria Unificada de Aceitação e Uso de Tecnologia (UTAUT), na qual o artigo se fundamenta, em seguida, na terceira seção, 
são descritos os procedimentos metodológicos adotados pera desenvolvimento da pesquisa e, na quarta seção são apresentados e discutidos os resultados, seguindo-se as considerações finais, na quinta seção.

\section{Revisão da Literatura}

\subsection{Tecnologia de Informação e Comunicação na Educação}

O mundo encontra-se num estado dinâmico, sendo caracterizado por várias mudanças, sejam elas culturais, sociais e políticas. Esse conjunto de alterações exigem da sociedade uma nova forma de enfrentar os desafios. Nesse contexto, a tecnologia aparece como um vetor importante na ocorrência e mediação dessas mudanças, havendo a necessidade de uso inteligente das TICs para uma melhor adaptação.

Morais, Alves, e Miranda (2013) destacam que atualmente o mundo se move rapidamente em meios digitais e informacionais, e o papel das TIC na educação está a tornar-se cada vez mais acelerado e com crescente importância no século XXI.

Neste contexto, Reis, Nobrega, Dantas, e Barroso (2018) explicam que a aplicação das TICs nas salas de aulas permitem aos alunos a aquisição de habilidades que lhes possibilitam agir perante novas práticas sociais em contextos específicos, sendo necessário que os mesmos consigam construir conhecimento a partir das TIC. Ainda nesta senda, os autores ressaltam a necessidade de o professor atuar como agente de uma nova prática educativa e metodológica, que conduza o aluno a operar de forma inteligente e com autonomia na aprendizagem.

Rosa e Cecílio (2010) reforçam que o uso das TICs na construção do conhecimento favorece a interdisciplinaridade, o entendimento crítico da realidade e o desenvolvimento humano, cultural, social e educacional. Apesar disso, acrescentam, que elas não são aplicadas ao processo de ensino-aprendizagem adequadamente, e muitos professores estão despreparados para inseri-las em suas práticas pedagógicas.

Bento e Prus (2011) explicam que o professor precisa entender de tecnologia e pedagogia para garantir um melhor desempenho no ensino aprendizagem do aluno. Corroborando, Reis (2016) afirma que no ensino superior, a presença das TICs tem promovido novos arranjos em relação aos processos de ensino-aprendizagem, exigindo dos professores diversas mudanças no modo de realizarem seus trabalhos.

Por sua vez, Bianchi e Hatje (2007) afirmam que uma das principais características da educação envolvendo as TICs é a de possibilitar o acesso às informações e uma descentralização do poder de comunicação na sala de aula, que estava centrado na figura do professor. Comprovando a idéia de descentralização do poder de comunicação na sala de aula, Garcia et al. (2012) salientam que nos últimos anos, em consequência dos avanços tecnológicos, houve um deslocamento do papel do professor, saindo de uma dimensão de especialista e detentor do conhecimento que instrui para o papel de um profissional da aprendizagem que incentiva, orienta e motiva o estudante.

Said-Hung (2012) argumenta sobre a importância das TICs na qualidade de ensino superior ao reforçar que conceitos como a flexibilidade, a mobilidade estudantil e docente, a geração de novos tipos de portfólios docentes e o aumento da eficiência no uso de materiais em tarefas docentes só é possível através da utilização das mesmas. Nesta linha de raciocínio, Nganga (2015) salienta que um dos maiores desafios a considerar é a necessidade de compreender a utilização e as funções de uma vasta gama de TIC existentes, sendo imperioso ajustar as aplicações adequadas para os alunos, para o conteúdo do curso, como também para o estilo de aprendizagem. A referida autora apresenta a síntese dos principais tipos de tecnologias mais utilizados, que podem ser visualizados no Quadro 1.

Maleane (2012) considera que, apesar do crescimento notório na utilização das TICs, há necessidade de se transpor algumas barreiras para que os benefícios delas sejam plenamente compartilhados. A autora acrescenta que dentre as várias barreiras que dificultam a democratização da informação, podem-se citar: a dificuldade de aquisição dos equipamentos que dão 
acesso a ela, a falta de uma política, as desigualdades sociais, culturais e econômicas.

Mesmo que as TICs desempenhem um papel preponderante nos processos acadêmicos no ensino superior, existem desafios quanto à sua aplicação no cotidiano das IES. Conforme Rosa e Cecílio (2010), a realidade escolar comporta um quadro em que as TICs ainda não são compreendidas por todos os professores, sequer como ferramentas pedagógicas potenciais na prática educacional com alunos. Porém, mesmo presentes no cotidiano escolar, poucos professores conhecem suas potencialidades educativas. Essa situação faz com que existem vários fatores que influenciam para aceitação e uso de tecnologia, sendo esses fatores alvo de muitas teorias que buscam compreendê-los.

Quadro 1: Tipos de tecnologias, exemplos e uso instrucional.

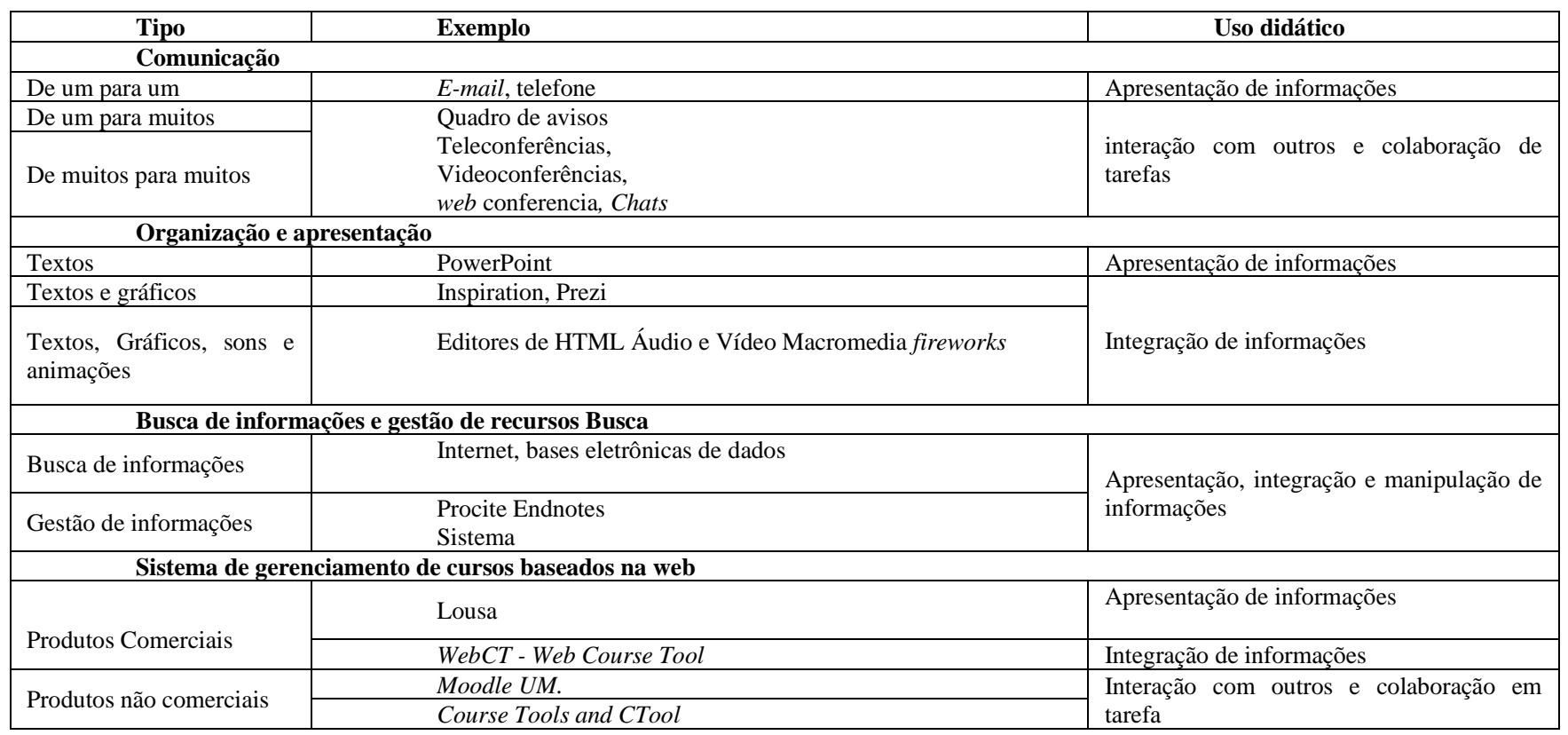

Fonte: Nganga (2015).

Conforme constatado na literatura, as TICs podem ter uma contribuição significativa na melhoria do processo de ensino aprendizagem. No entanto, a adoção dessas tecnologias ocorre em um ambiente complexo em que professores e alunos podem enfrentar dificuldades na utilização. Tal cenário pode ser mais desafiador no contexto de IES públicas de uma país em desenvolvimento como Moçambique. Ao mesmo tempo, a utilização das TICs por professores e alunos podem trazer um avanço para o país no sentido de garantir a assistência aos estudantes na aquisição de conhecimentos de forma efetiva e eficiente. A utilização das TICs na educação permite que os estudantes busquem, selecionem, organizem, interpretem e avaliem criticamente a informação, bem como a criação de ambientes criativos e inovadores de aprendizagem.

\subsection{O Contexto das TIC no Ensino Superior em Moçambique}

A República de Moçambique é um país que se localiza no sudeste da África, com uma superfície total de 799.380 quilômetros quadrados, e uma população estimada em cerca de 28 milhões de pessoas em 2017. O país apresenta um índice de pobreza de $87,5 \%$ e a maioria da população residindo na zona rural (66,5\%), vivendo abaixo da linha da pobreza e com carência de serviços básicos, tais como o acesso a água potável, instalações de saúde e escolas (IFAD, 2018 \& INE, 2019). Esta situação faz com que ele esteja classificado como um dos países mais pobres do mundo, ocupando a posição 180 de 189 países, com IDH de 0,446 (UNDP 2020).

Nos esforços de combate à pobreza, Moçambique foi um dos primeiros países africanos a reconhecer a importância do 
uso das TIC para promover o desenvolvimento e a necessidade estratégica de priorizar a sua integração por meio de planos e programas de desenvolvimento do país (Maleane, 2012). Nesta perspectiva, o governo Moçambicano aprovou no ano 2000 uma Política de Informática que considerava as TICs como um motor de desenvolvimento, em que a informação desempenhou um papel fundamental em todos os setores socioeconômicos, tais como: setor produtivo, na educação, na saúde, na prestação de serviços públicos, na justiça, na sociedade, bem como em todos as componentes relacionadas com a boa governaça (Moçambique, 2018).

A educação, o desenvolvimento de recursos humanos, a saúde, o acesso universal, a infraestrutura nacional de suporte às TICs e governança foram consideradas as áreas prioritárias no âmbito da Política Nacional de Informática. Nesta senda, Ginger (2017) afirma que a utilização das TICs na área educação e no desenvolvimento de recursos é vista como ponto de partida para a adoção das TICs noutras áreas definidas como prioritárias no âmbito da política em referência.

Assim, para a área de educação a Política de Informática estabelece como estratégia de intervenção o incentivo e o desenvolvimento do ensino de informática nos diferentes níveis de ensino do sistema nacional de educação, e também generalizar o uso de internet nas escolas, preparar os professores para serem promotores das TICs nas escolas, dotar as escolas do país com o equipamento indispensável ao acesso e domínio das TICs, entre outras. Para a área de desenvolvimento humano, a política prevê definir perfis de profissionais para TICs, regras para a atividade e funcionamento de centros de formação nesta área, criar centro de excelências para formação de profissionais e para aplicação de soluções informáticas, promover formação em informática através de ensino a distância, entre outras (Ali \& Abibo, 2018; Ginger, 2017).

Ali e Abibo ( 2018) discorrem que para implementação da Política de Informática em Moçambique foi aprovada, no ano de 2002, a Estratégia de Implementação, que serviu como meio para operacionalização de projetos a curto, médio e longo prazos nas seis áreas prioritárias dessa política, que têm como suporte a utilização das TICs. Ginger (2017) traz que foram identificados um total de 37 programas e projetos em áreas prioritárias, e alguns estavam relacionados com a introdução das TICs no sistema de educação e desenvolvimento de recursos humanos.

Na visão de Ali e Abibo (2018), os referidos projetos foram colocados num programa integrado de ação, objetivando responder às necessidades de criação da capacidade humana, desenvolver e modernizar a infraestrutura, produzir conteúdo e aplicações, elevar a eficácia na governaça e criar um ambiente legal propício ao desenvolvimento empresarial.

Conforme Maleane (2012), o aumento dos recursos humanos com elevadas habilidades, a expansão e modernização da infraestrutura de telecomunicações no país e a aceleração da definição da política de telecomunicações constituem os desafios da estratégia para a expansão das TICs em Moçambique. Por seu turno, Mabila (2013) demonstra a relevância da criação de uma estrutura robusta e moderna de infraestrutura de rede nacional, como pré-requisito para alavancar o desenvolvimento de um sistema de informação da sociedade em Moçambique. O mesmo autor acrescenta que a prioridade chave foi dada a única operadora das Telecomunicações de Moçambique (TDM), criando a expansão da cobertura de rede e substituição de tecnologias antigas por outras mais modernas.

Quanto ao papel das IES neste processo, importa referir que a política de informática reconheceu o seu papel fundamental no processo de implementação das metodologias e soluções de utilização e expansão das TICs na melhoria das condições de vida dos cidadãos, por meio de encorajamento na invenção de produtos e serviços de qualidades dos seus formandos. Portanto, entre várias responsabilidades atribuídas às IES, no âmbito da referida política, destacam-se: expandir e consolidar a utilização das TICs, dar destaque a formação em informática nos currículos de Ciência e Tecnologia, utilizar as TICS para expandir o acesso ao ensino superior, liderar as testagens de novas TIC dando recomendações sobre ações prioritárias ao governo, publicar e divulgar sistematicamente os resultados de pesquisa e experimentação utilizando as TICs, entre outras atividades (Moçambique, 2000).

Nesse contexto, Salimo e Gouveia (2017) afirmam que no ano 2005, o Ministério da Ciência e Tecnologia criou a 
Rede de Educação e Pesquisa de Moçambique (MORENET), que é uma rede de dados de âmbito nacional que interliga instituições acadêmicas de ensino superior e de pesquisa, desenvolvendo atividades sem fins lucrativos. Os autores ressaltam ainda que a MORENET tem os seguintes objetivos: (i) fornecer serviços de interligação e acesso à Internet as Instituições Nacionais de Ensino Superior e Pesquisa; (ii) Interligar o Sistema Nacional de Ensino Superior e da Ciência, Tecnologia e Inovação para o mundo exterior através de estabelecimento de parcerias institucionais com outras redes de Ensino Superior; (iii) Estabelecer uma plataforma comum para fornecer serviços compartilhados para as instituições de ensino superior e de pesquisa; (iv) Fornecer serviços de suporte de rede, e (v) Promover serviços de formação em TICs, entre outros.

Fernando (2016) esclarece que em consequência destes esforços do governo em transformar as TICs como motor para o desenvolvimento, Moçambique tem mostrado tendências crescentes de seu uso - com o aumento nos indicadores de utilização de telefones móveis, da internet e de computadores. Por outro lado, dados fornecidos pela política de Sociedade de informação (2018), mostram que em 2016 houve uma redução de cadastros na rede de telefonia fixa em que se registou 87.758 contra 13.086.554 cadastros de telecomunicações móveis no mesmo período. O mesmo documento refere-se que em 2017, a percentagem de assinaturas de telefone fixo por 100 habitantes é de $0,30 \%$, com assinaturas fixas (com fio) de banda larga por 100 habitantes é de 0,14\% e percentagem de domicílios com acesso à Internet é de 16,17\%.

No caso particular do ensino superior, (Salimo \& Gouveia, 2017) argumentam que um grande número de IES não tem acesso a MoRENet. Ademais, as IES que já se beneficiaram têm problemas de acesso (interrupção sistemáticas, lentidão na transmissão, inoperacionalidades de serviços, e problemas técnicos de perda de sinal).

Em resumo, percebeu-se, com base nessas discussões, que apesar das dificuldades na implementação da política de informática de Moçambique, constatou-se avanço no uso das TICs. No âmbito do ensino superior, ainda há desafios no que tange a sua utilização integrada nos diferentes setores das IES, seja no ensino, pesquisa, extensão bem como na gestão de processos acadêmicos. Portanto, para que a integração das TIC no cotidiano das IES seja adequada, é imprescindível a participação de todos os atores das IES do país, ou seja, os estudantes, professores, dirigentes e membros do corpo técnico administrativo.

\subsection{A Teoria Unificada de Aceitação e Uso de Tecnologia (UTAUT)}

A preocupação com os fatores que levam as pessoas a aceitarem e a usarem a tecnologia nas organizações, tem sido objeto de debate entre pesquisadores dando origem a muitas teorias, cada uma tentando explicar as causas que conduzem à adesão ou à aversão para o uso das TIC nas organizações.

$\mathrm{Na}$ busca de um modelo que pudesse integrar os aspectos essenciais de cada uma das teorias de aceitação e uso das TICs, Venkatesh et al. (2003) desenvolveram um modelo denominado Unified Theory of Acceptance and Use of Technology (UTAUT). Este modelo integra elementos de oito modelos que lidam com o assunto sobre aceitação do uso da tecnologia nas organizações, a saber: Teoria da Ação Racional (TRA), Modelo de Aceitação da Tecnologia (TAM), Modelo Motivacional (MM), Teoria do Comportamento Planejado (TPB), Modelo Combinado TAM-TPB, Modelo de Utilização do PC (MPCU), Teoria da Difusão da Inovação, aplicada em Sistema de Informação (SI) e Teoria Social Cognitiva (Bobsin, Visentini, \& Rech, 2009; Chao, 2019; Gonzales et al., 2017; Marques, Behr, \& Malanovicz, 2021).

Chao (2019) menciona que o modelo UTAUT resulta de uma análise sistemática e comparação das modelagens mencionadas, com a capacidade que pode explicar $70 \%$ da variância na intenção do usuário. Para tanto, validação foi feita mediante a aplicação destas teorias em quatro empresas diferentes e, a partir dos resultados obtidos, foram verificadas similaridades entre os construtos utilizados em cada abordagem, selecionando aqueles com maior poder de explicação e escolhidos os moderadores que demonstraram um efeito mais forte sobre os antecedentes da intenção de uso (Marques et al., 2021). 
O modelo UTAUT é composto por 4 fatores determinantes que são os construtos de maior influência na intenção de uso e no comportamento de uso presentes em um ou mais modelos anteriores (Castro, Duarte, Momo, Behr, \& Bonato Marcolin, 2020; Gonzales Jr et al., 2018; Marques et al., 2021). Este grupo de fatores inclui: i) expectativa de desempenho; expectativa de esforço; a influência social e condições facilitadoras.

Para além dos fatores determinantes, o Modelo UTAUT também é composto por condições moderadoras que são os fatores indiretos que mais influenciam a intenção de uso e comportamento de uso, nestes pode-se incluir: gênero, idade, experiência e voluntariedade (Marques et al., 2021). Na Figura 1 estão representadas as relações entre os construtos do modelo UTAUT.

Figura 1: Teoria Unificada de Aceitação e Uso da Tecnologia.

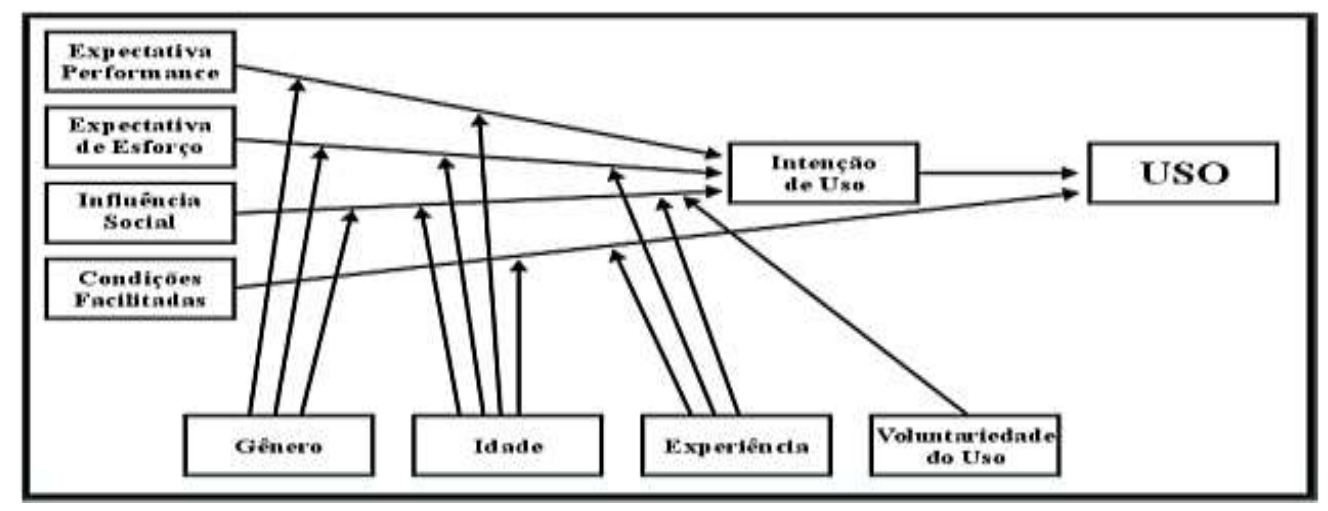

Fonte: Venkatesh et al. (2003).

A expectativa de desempenho é definida por (Venkatesh et al., 2003) como o grau em que um indivíduo acredita que o uso do sistema o ajudará a obter ganhos do desempenho no trabalho. Os autores em referência consideram a expectativa de desempenho como o preditor mais forte de intenção de uso, sendo ele moderado pelo gênero e idade, se mostrando mais forte para homens mais jovens.

Conforme Venkatesh et al. ( 2003) a expectativa de esforço é o grau de facilidade associado ao uso do sistema, sendo ele moderado pela idade, gênero e experiência profissional. Os autores referem-se ainda ao efeito da expectativa de esforço como sendo mais forte para as mulheres, particularmente mais jovens e nos estágios iniciais da experiência.

Por seu turno, a influência social é definida como o grau em que um indivíduo percebe que outras pessoas importantes acreditam que ele deve usar o novo sistema (Venkatesh et al., 2003). Os achados destes autores demostraram também que a presença da influência social na intenção de uso que será moderada por gênero, idade, voluntariedade e experiência. Portanto, o efeito será mais forte para as mulheres, particularmente mulheres mais velhas e em ambientes obrigatórios nos estágios iniciais de experiência.

Quanto as condições facilitadoras Venkatesh et al. (2003), definem-nas como o grau em que um indivíduo acredita que existe uma infraestrutura organizacional e técnica para apoiar o uso do sistema. Assim, elas serão moderadas pela idade e experiência, de modo que o efeito será mais forte para os trabalhadores mais velhos, particularmente com o aumento da experiência.

\subsubsection{Pesquisas utilizando o modelo UTAUT}

Muitas têm sido as pesquisas que aplicam o modelo UTAUT dependendo de contextos, objetivos e áreas de conhecimento. A seguir apresentam-se algumas pesquisas encontradas por este estudo e que aplicaram o modelo em referência.

Moreno \& Silva, (2009) analisaram a aplicação do Modelo UTAUT a Processos de Adoção de Sistemas ERP. A 
coleta de dados foi feita aplicando um questionário via internet, que foram analisados através da regressão linear múltipla, sendo obtidos resultados que indicaram que quanto maior a expectativa de desempenho e a influência social, maior a intenção de uso do sistema ERP, e que o efeito moderador da idade na relação entre influência social e intenção de uso, e gênero, na expectativa de desempenho influenciam positivamente a intenção de uso.

O estudo de Pereira, Ramos, Nogueira, Gomes, e Mól (2013), utilizou a Teoria Unificada de Aceitação e Uso da Tecnologia (UTAUT) para identificar as relações entre os construtos deste modelo e o padrão de uso do sistema Moodle com estudantes do curso a distância de administração pública numa universidade federal. Por meio de aplicação de um survey e da modelagem de equações estruturais (SEM), foi comprovado que a intenção de uso é explicada pela expectativa de desempenho do usuário e, por seu turno, o padrão de uso é explicado pela intenção de uso e pelas condições facilitadoras.

A pesquisa de Castro (2014) aplicou o modelo UTAUT em uma empresa de pequeno porte para avaliar a aceitação de um ERP na área de Contabilidade da empresa. Os resultados indicaram maiores dificuldades no tratamento de informações contábeis com base no ERP, mesmo após dois anos de implementação do sistema, as informações ainda são tratadas manualmente. $\mathrm{O}$ outro achado da referida pesquisa indica que o fator idade era um fator que contribuía para a não utilização do sistema, isto é, quanto mais velhos forem os usuários, menor a disposição para aceitar o ERP. Quanto aso fatores determinantes, ficou evidente que os usuários perceberam os ganhos trazidos pelo novo sistema para o desempenho organizacional; indicando que o esforço foi válido e que a prática facilitou a aprendizagem.

O estudo de Almeida e Albertin (2014) também utilizou o modelo UTAUT na análise da intenção de uso de uma rede social virtual corporativa por parte dos seus usuários. Os dados foram coletados por meio de um questionário eletrônico criado no ambiente Surveymonkey tendo recebido 96 respostas validas. Os resultados da análise multivariada de Modelagem por Equações Estruturais, levou nos pesquisadores a concluírem que quanto menor a expectativa de esforço, maior as condições facilitadoras, tanto maior é a intenção de uso da rede social virtual corporativa na empresa.

O modelo UTAUT foi aplicado para de identificar e analisar os fatores que influenciam a aceitação do uso de recursos tecnológicos aplicados nos cursos de pós-graduação stricto sensu em Ciências Contábeis (PPGCCs), na percepção dos docentes. A pesquisa obedeceu a abordagem quantitativa, por meio da aplicação da análise fatorial confirmatória e da análise de regressão múltipla. Os resultados da pesquisa indicaram que os construtos Expectativa de Desempenho e Expectativa de Esforço foram aqueles com efeito significativo sobre a Intenção de Uso de recursos tecnológicos por parte dos docentes dos PPGCCs (Nganga, 2015).

Silva, Dornelas, e Araujo (2020) analisaram a satisfação de professores com ferramentas para realização de aulas remotas durante a pandemia da COVID-19 em função dos constructos autoeficácia, estilo de trabalho e testabilidade. Esses autores basearam-se no modelo de aceitação de tecnologia (TAM), a Teoria Unificada de Aceitação e Uso de Tecnologia (UTAUT) e o Modelo de Fatores de Sucesso de Sistemas de Informação, de DeLone e McLean. A coleta de dados foi feita por meio de survey realizada com 65 professores de instituições de ensino superior e, utilizando-se da regressão logística como técnica de análise, foi possível verificar que os três construtos têm forte influência na satisfação do professor quanto a utilização ferramentas tecnológicas para a execução das aulas remotas.

Marques et al. (2021), adotaram metodologia qualitativa em seu estudo de caso sobre avaliação da aceitação de um ERP no Departamento Contábil de uma empresa pública, recorrendo a entrevistas semiestruturadas, análise documental, observação, e análise de conteúdo. Os resultados mostraram que as expectativas dos usuários estavam acima do que foi percebido após a implantação do sistema integrado, gerando neles a sensação de frustração e impactando negativamente a intenção de uso.

A partir do exposto, verifica-se que o modelo UTAUT é amplamente utilizado em diferentes tipos de pesquisa. Assim pelo seu maior poder preditivo em relação aos outros oito modelos anteriores, o presente estudo irá utilizar os constructos 
validados pelo modelo UTAUT, com objetivo de identificar os fatores determinantes da tendência do uso das TIC entre os professores das IES da província de Manica, considerando-se que eles podem ser influenciados por muitos fatores de contextos que, de certa forma, podem encorajar ou desencorajar o uso das TIC. Feitas as considerações sobre o modelo UTAUT e a sua aplicação em pesquisas, a seguir apresentam-se os passos metodológicos trilhados para desenvolver a pesquisa

\section{Metodologia}

\subsection{Classificação da pesquisa}

Quanto a sua natureza a pesquisa pode ser considerada como quantitativa, por recorrer as técnicas estatísticas no processo coleta, tratamento e análise de dados (Nganga, 2015; Pereira; Shitsuka; Pereira \& Shitsuka, 2018; Raupp \& Beuren, 2006). Quanto aos objetivos esta pesquisa classifica-se como descritiva na medida que faz a discrição das características de uma determinada população (Gil, 2008). Para tanto, o estudo dedicou-se na identificação e descrição dos fatores condicionantes para a tendência de uso das TICs entre os professores das IES publicas da província de Manica quanto aos procedimentos a pesquisa é caracterizada como Levantamento de campo (survey), tendo em conta que foram aplicados questionários diretamente aos professores com intuito de perceber o seu comportamento quanto os fatores que condicionam a tendência de uso das TICs. Gil (2008) refere que no levantamento de campo, solicita-se informações um grupo significativo de pessoas acerca do problema estudado, e seguidamente obtém-se conclusões dos dados mediante análise quantitativa.

\subsection{População, Amostra e Dados da Pesquisa}

Considerou-se como local de estudo a República de Moçambique, especificamente a província de Manica. A escolha desse local fundamenta-se no fato de ser uma região em processo de desenvolvimento, que reflete o contexto vivido no país, onde se identifica uma série de aspectos sociais e materiais afetados negativamente pela guerra civil ocorrida no período de 1977 a 1992. Considerando-se que após a ocorrência de tal cenário foram adotadas diversas medidas, em âmbito nacional, no sentido de reestruturar as infraestruturas locais, reatar o desenvolvimento socioeconômico e prover melhores condições de vida à sociedade, dentre as quais a aprovação da Política Informática, no ano 2000, quando passou a vigorar.

A República de Moçambique é um país com grandes níveis de desigualdade econômica entre as regiões, sendo a região sul a mais desenvolvida e as regiões e centro e norte as menos desenvolvidas. Portanto, a escolha de província de Manica, fundamenta-se por esta se localizar na região centro do país com baixo nível de desenvolvimento econômico, pelo que se considera que a partir da análise da percepção dos professores quanto ao uso das TICs pode-se favorecer o entendimento sobre como a política nacional das TICs está sendo implementada, podendo-se refletir de forma abrangente em todas as regiões do País.

Cabe destacar, que os objetos de estudo foram as IES, uma vez que estas desempenharam papel preponderante como parceiros na implementação da Política Informática, sendo responsáveis por desenvolver soluções que permitissem a expansão da utilização das mesmas. Nesse contexto, ressalta-se a necessidade de perceber os reflexos de tal política, especificamente nas IES, haja vista os montantes dispendidos de recursos governamentais e humanos com a finalidade de expandir os sistemas de comunicação, tornando possível o acesso às informações disponibilizadas.

Para tanto, quanto à coleta de dados, utilizou-se como instrumento um questionário, por meio da ferramenta Google Docs ${ }^{\circledR}$, disponibilizado via e-mail para os docentes das IES públicas da província de Manica, vislumbrando os 207 professores existentes. Contudo, obteve-se um retorno de 103 respostas dos questionários enviados, que corresponde a uma taxa de retorno de cerca de 50\%. Percentual considerado adequado e representativo.

O questionário enviado foi subdividido em três partes, sendo a primeira destinada à coleta de dados sociodemográficos sobre os docentes, incluindo doze variáveis, nomeadamente: Sexo, Idade, Nível de escolaridade, Cursos de 
Formação, IES de afetação (lotação), níveis de formação lecionados, experiência na docência, disciplinas lecionadas, tipo de equipamento existente na sala de aula, participação em cursos de curta duração, utilização da tecnologia na sala de aula e tempo de utilização da tecnologia.

A segunda parte foi composta de dez afirmações que visavam medir o nível de utilização dos diferentes tipos de tecnologias utilizados pelos professores nas salas de aulas por meio de uma escala tipo Likert. A escala variou de 1 a 8 pontos, onde 1 a 5 corresponde a (tendência de baixa utilização), 6 a 8 a (tendência para alta utilização da tecnologia). Cabe salientar que o instrumento de coleta de dados aqui utilizado, baseou-se, em adaptação do utilizado por Nganga (2015).

Por sua vez, a terceira parte foi composta por trinta e duas afirmações que tinham por objetivo avaliar a influência dos constructos determinantes e moderadores para aceitação do uso de tecnologia baseados no modelo UTAUT, adaptados dos instrumentos de coleta de dados de Nganga (2015). Portanto, para o caso particular deste estudo, não foram considerados os constructos intenção de uso, tendo em conta que o objetivo fundamental era analisar a tendência de uso, e a voluntariedade de uso, pois no contexto em análise o uso de tecnologia ainda não é obrigatório. O modelo de análise adaptado para esta pesquisa encontra-se representado na Figura 2.

Figura 2: Modelo analítico adaptado para esta pesquisa.

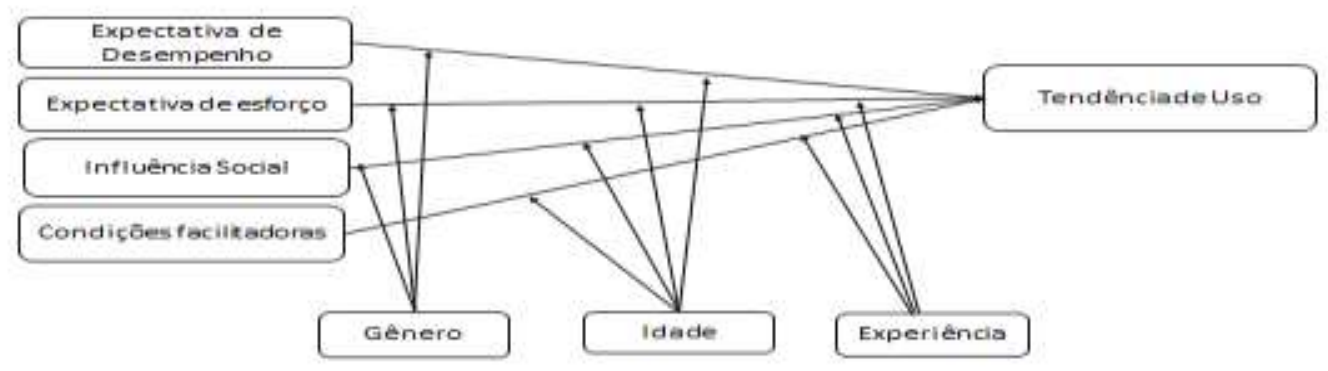

Fonte: Adaptado de Venkatesh et al. (2003).

Ressalta-se que nesta terceira etapa também foi utilizada uma escala tipo Likert contendo perguntas que avaliavam as variáveis relacionadas às dimensões do modelo UTAUT. A escala variou de 1 a 8 , onde 1 a 3 correspondia a discordo totalmente e níveis sequenciais de discordância (avaliação mais negativa), 3 a 5 posicionamento neutro e de 6 a 8 correspondia à afirmativas com níveis sequenciais de concordância até concordo totalmente (avaliação positiva).

\subsection{Modelagem dos testes estatísticos e variáveis utilizadas}

Primeiramente, realizou-se uma Análise Exploratória de Dados (Hair et al., 2005), a partir da qual foram caracterizados os docentes das IES públicas da província de Manica e o nível de utilização das tecnologias existentes por parte dos mesmos.

Em seguida, optou-se por aplicar a técnica da Análise Fatorial, que objetiva a geração de fatores subjacentes não observados frente a presença de muitas variáveis observadas (Hair et al., 2005; Corrar; Paulo; Dias Filho, 2007). Em outras palavras, tal método consiste em reduzir uma grande quantidade de variáveis observadas a um número menor de fatores, sendo este último entendido como medidas que não podem ser diretamente observadas (Figueiredo Filho; Silva Júnior, 2010).

Para os objetivos do estudo, optou-se pela utilização da técnica da Análise Fatorial para demonstrar como os aspectos determinantes e moderados relacionados a este processo, baseados no modelo UTAUT, uma vez que podem ser sumarizados em um menor número de fatores, haja vista a grande quantidade de questões nos instrumentos de coleta de dados.

Complementarmente, após a obtenção dos fatores, optou-se pela adoção da Regressão Logística Múltipla Binomial, uma vez que a variável dependente do modelo proposto possui característica qualitativa, expressa por valores 0 ou 1 , em um 
dado contexto onde se identifica mais de uma variável independente. Sendo assim, sugerido tal modelo de regressão foi usado para se prever a probabilidade de ocorrência de um determinado evento (Hair et al., 2005; Figueira, 2006; Fávero, 2015). Assim, o modelo é representado pela equação 1 .

$$
Z_{\mathrm{i}}=\alpha+\beta_{1}, X_{1 \mathrm{i}}+\beta_{2} \cdot X_{2 \mathrm{i}}+\beta_{3} \cdot X_{\mathrm{ai}}+\cdots+\beta_{k}, X_{\mathrm{ki}}+\varepsilon
$$

Em que:

Z é a variável binária que assume valor um caso haja mais tendência de uso e zero, caso contrário;

$\alpha$ é a constante;

$\beta$ são os parâmetros estimados de cada variável explicativa;

X são as variáveis explicativas - Variáveis descritas no Quadro 2.

A utilização de tal método se justifica frente a necessidade de se explorar a influência dos constructos determinantes e moderadores (estes transformados em fatores) juntamente com as demais variáveis explicativas obtidas por meio do questionário aplicado, na tendência do uso (ou não) das tecnologias de informação e comunicação pelos docentes das IES públicas da província de Manica.

Há de se mencionar que a variável dependente foi obtida por meio da escala somada referente às perguntas sobre o nível de utilização das tecnologias. Posteriormente, efetuou-se o cálculo da média e desvio padrão da mesma, objetivando-se delimitar a escala da variável, onde aqueles respondentes com valores acima da média somada a um desvio padrão foram classificados como 1 (Mais tendência de uso), enquanto os respondentes abaixo deste cálculo obtiverem a escala 0 (Menos tendência de uso).

Quadro 2: Variáveis utilizadas no modelo, coleta crossection.

\begin{tabular}{|c|c|c|c|}
\hline Variáveis & Descrição & $\begin{array}{l}\text { Expectativa } \\
\text { Teórica }\end{array}$ & Autores \\
\hline $\begin{array}{l}\text { Tendência de Uso de Tecnologia em sala de aula } \\
\text { (Uso de Tec) }\end{array}$ & $\begin{array}{l}\text { Situação dos professores terem alta ou } \\
\text { baixa tendência de utilização das TICs }\end{array}$ & Dependente & Venkatesh et al. (2003). \\
\hline$x^{2}$ & $\begin{array}{l}\text { Número total de professores do sexo } \\
\text { masculino e feminino. Dummy: (1) - } \\
\text { mulher; }(0) \text { - homem. }\end{array}$ & + & $\begin{array}{l}\text { Venkatesh et al. (2003); } \\
\text { Venkatesh et al. (2012) }\end{array}$ \\
\hline Experiência Acadêmica (Experiência) & $\begin{array}{l}\text { Tempo de docência dos professores nas } \\
\text { IES medido em termos de anos de } \\
\text { experiência }\end{array}$ & + & $\begin{array}{l}\text { Venkatesh et al. (2003), Tacco } \\
\text { (2011) }\end{array}$ \\
\hline Fator 1. Expectativa de desempenho) & $\begin{array}{l}\text { Nível de crença dos professores sobre os } \\
\text { ganhos oriundos da utilização das TICs }\end{array}$ & + & $\begin{array}{c}\text { Venkatesh et al. (2003), Nganga } \\
\text { (2015), Tacco (2011), Pereira et } \\
\text { al., (2013), }\end{array}$ \\
\hline Fator 2 (Condiçōes Facilitadoras ) & $\begin{array}{l}\text { Nível de crença dos professores quanto a } \\
\text { existência de infraestruturas e condições } \\
\text { técnicas para o uso das TICs }\end{array}$ & + & $\begin{array}{l}\text { Venkatesh et al. (2003), Faria et } \\
\text { al. (2014), Meirelles e Longo } \\
\text { (2015), Tacco (2011) }\end{array}$ \\
\hline Fator 3 (Expectativa de esforco) & $\begin{array}{l}\text { Nível de crença dos professores quanto } \\
\text { ao grau de facilidade no uso das TICs }\end{array}$ & + & $\begin{array}{l}\text { Venkatesh et al. (2003), Faria et } \\
\text { al. (2014), Cappellozza e } \\
\text { Meirelles (2014) }\end{array}$ \\
\hline Fator 4 (Influência Social) & $\begin{array}{l}\text { Grau de crença quanto a influência das } \\
\text { outras pessoas da importância do uso das } \\
\text { TICs }\end{array}$ & + & $\begin{array}{l}\text { Venkatesh et al. (2003), Tacco } \\
\text { (2011) }\end{array}$ \\
\hline
\end{tabular}

Fonte: Dados da pesquisa.

Com base nas variáveis apresentadas no Quadro 2, o modelo estimado para o presente estudo consiste em:

Uso de Tec $c_{t}=\alpha_{0}+\beta_{1}$. Expectativa de desempenho ${ }_{t}+\beta_{2}$. Influência Social $t_{t}+$ $\beta_{\mathrm{a}^{*}}$. Condições Facilitadoras $t_{\mathrm{t}}+\beta_{4^{*}}$ Expectativa de esforço $o_{\mathrm{t}}+\beta_{5}$. Sexo $_{\mathrm{t}}+\beta_{6}$ Experiência $_{\mathrm{t}}+\varepsilon_{\mathrm{t}}$ 


\section{Resultados e Discussão}

\subsection{Análise Descritiva dos Dados}

Inicialmente, realizou-se uma análise descritiva dos dados com o intuito de identificar o perfil dos professores das IES públicas da província de Manica, Moçambique. Na Tabela 1 estão apresentados os dados sociodemográficos da amostra.

Notou-se que os respondentes, em sua maioria, são do sexo masculino (77,7\%), com idade compreendida entre 30 a $35 \operatorname{anos}(33 \%)$, tendo como nível de formação mestrado (66\%) em Ciências Sociais $(31,1 \%)$. Além disso, eles lecionam nos cursos de licenciatura $(92,2 \%)$ e possuem um tempo média de docência entre 6 a 10 anos.

Quanto à variável gênero, importa referir que o relatório de estudos sobre o assunto em Moçambique (2013) evidencia que o desequilíbrio existe no ensino superior. Isso pode ser justificado em parte como consequência das dinâmicas das relações de gênero do Ensino Primário/Secundário marcadas, por um lado, pelo acesso irregular das mulheres à escola e desistências por motivos de gravidez ou casamentos prematuros. Por outro lado, o estudo de Uamusse e Kouleshova (2020) demostra que Governo de Moçambique já possui políticas voltadas à promoção da equidade e igualdade de gênero, tais como: o Plano Nacional para Avanço da Mulher (2006), a Política de Gênero e Estratégia, de Implementação (2006), a Estratégia de Gênero para a Função Pública (2009), Estratégias de Gênero para o Sector da Educação, entre outros. Portanto, espera-se que nos próximos anos haja uma melhoria da participação da mulher no ensino superior.

A predominância de idade entre 30 a 35 anos, na amostra dos respondentes, pode ser explicada pela própria Lei do ensino no sistema nacional de educação de Moçambique, em que o ensino superior é frequentando por jovens que concluíram as 12 classes, que são concluídas normalmente aos 25 anos e depois os formados podem lecionar.

Tabela 1: Descrição do perfil dos professores das IES de Manica.

\begin{tabular}{|c|c|c|}
\hline Variável & Alternativa de resposta & Frequência (\%) \\
\hline Sexo & $\begin{array}{l}\text { Masculino } \\
\text { Feminino }\end{array}$ & $\begin{array}{l}77,7 \\
22,3\end{array}$ \\
\hline Idade & $\begin{array}{l}\text { Até } 25 \text { anos } \\
25 \text { a } 30 \text { anos } \\
30 \text { a } 35 \text { anos } \\
35 \text { a } 40 \text { anos } \\
40 \text { a } 45 \text { anos } \\
45 \text { a } 50 \text { anos } \\
50 \text { a } 55 \text { anos } \\
\end{array}$ & $\begin{array}{l}1,0 \\
16,5 \\
33,0 \\
32,0 \\
10,7 \\
2,9 \\
3,9 \\
\end{array}$ \\
\hline Formação Académica & $\begin{array}{l}\text { Licenciatura } \\
\text { Mestrado } \\
\text { Doutorado }\end{array}$ & $\begin{array}{l}26,2 \\
66,0 \\
7,8\end{array}$ \\
\hline Tempo de exercício na docência & $\begin{array}{l}\text { Até } 2 \text { anos } \\
3 \text { a } 5 \text { anos } \\
6 \text { a } 10 \text { anos } \\
\text { Mais de } 10 \text { anos }\end{array}$ & $\begin{array}{l}5,8 \\
21,4 \\
50,5 \\
22,3\end{array}$ \\
\hline Níveis lecionados & $\begin{array}{l}\text { Licenciatura } \\
\text { Mestrado } \\
\text { Doutorado }\end{array}$ & $\begin{array}{l}92,2 \\
6,8 \\
1,0 \\
\end{array}$ \\
\hline Áreas de formação & $\begin{array}{l}\text { Educação } \\
\text { Letras e Humanidades } \\
\text { Ciências Sociais } \\
\text { Ciências Naturais } \\
\text { Engenharia manufatura e de construção } \\
\text { Engenharia Agrícola, Florestal e Veterinária } \\
\text { Serviços }\end{array}$ & $\begin{array}{l}6,8 \\
13,6 \\
31,1 \\
10,7 \\
11,7 \\
25,2 \\
1,0\end{array}$ \\
\hline IES de atuação & $\begin{array}{l}\text { ISPM } \\
\text { UNIPUNGUE } \\
\text { UNIZAMBEZE -FEARN } \\
\text { ESJ }\end{array}$ & $\begin{array}{l}37,9 \\
30,1 \\
20,4 \\
11,7\end{array}$ \\
\hline
\end{tabular}

Nota: ISPM - Instituto Superior Politécnico de Manica; UNIPUNGUE - Universidade do Púnguè; UNIZAMBEZE- FEARN - Universidade do Zambeze Faculdade de Engenharia Ambiental e de recursos Naturais; ESJ -Escola Superior de Jornalismo Delegação de Manica Fonte: Dados da pesquisa.

Os resultados desta pesquisa indicam o predomínio das ciências sociais como áreas de formação dos docentes que 
compuseram a amostra da pesquisa. Esta situação pode estar associada à priorização que o Governo moçambicano deu as áreas de educação e ciências sociais após a independência, como medida para garantir a formação de professores e de quadros pessoais para atenderem os setores de economia do país (Cossa, Buque, \& Premugy, 2019). Por outro lado, o baixo número de professores formados em educação justifica-se por esta área não fazer parte dos cursos ofertados pelas IES em análise. A presença de mais docentes que lecionam os cursos de licenciatura deve-se a existência de poucas IES que oferecem cursos de pós-graduação na amostra, sendo apenas quatro cursos de mestrado, sendo um de UNIZAMBEZE-FEARN, um da UNIPUNGUE e dois do ISPM.

A representação de professores com o nível de mestrado pode ser explicada pela preocupação do governo na formação de professores. Isso é decorrente da Estratégia de Formação de Professores do Ensino Superior (2009-2015), com vista à elevação do nível acadêmico em áreas especializadas. De acordo com o Plano estratégico do ensino superior (2010), o quadro de professores em tempo integral apresentou cerca de 1.200 docentes nas categorias de assistente e professor auxiliar, tanto nas instituições públicas como nas privadas. Deste número, apenas $15 \%$ possuem o nível de doutoramento e $25 \%$ o de mestrado. Os restantes (60\%) são licenciados ou bacharéis. Quanto à participação de maior parte de respondentes serem do ISPM é devido a ser a primeira (e maior) instituição de ensino superior a ser estabelecida na província de Manica, desde 2006.

A outra componente que fez parte da análise descritiva dos dados, foi a apresentação dos níveis de uso da tecnologia e as mais usadas pelos professores das IES da província de Manica. Para isso, tomou-se como base o cálculo da média aritmética e desvio padrão para cada uma das variáveis incorporadas na escala tipo Likert. Na Tabela 2 estão apresentados os resultados encontrados.

Tabela 2: Nível de utilização de tecnologia pelos professores.

\begin{tabular}{|c|c|c|c|}
\hline \multirow[t]{2}{*}{ Tipo de tecnologia utilizada } & \multicolumn{2}{|r|}{$\mathbf{M}$} & \multirow[t]{2}{*}{ Desvio } \\
\hline & édia & padrão & \\
\hline Tecnologia de informação de 1 para 1 (exemplo e-mails, teleconferências e vídeos) &, 92 & 3 & 2,29 \\
\hline $\begin{array}{l}\text { Tecnologia de informação de muitos para muitos (bate-papo; chats, fórum de discussão; troca de arquivos, blogs, } \\
\text { redes sociais, tweeters) }\end{array}$ & ,36 & 3 & 2,27 \\
\hline Tecnologia de áudio e vídeo (podcast; vodcast, webcast, youtube, vídeos) &, 53 & 5 & 2,39 \\
\hline $\begin{array}{l}\text { Tecnologia de organização e apresentação: Textos, gráfico animação Powerpoint, mapas conceituais, imagens } \\
\text { animadas, flash) }\end{array}$ & ,90 & 4 & 2,24 \\
\hline Tecnologia de busca de informação (internet base de dados eletrônicas de dados, bookmarking) &, 28 & 3 & 2,27 \\
\hline Tecnologia de criação de conteúdo colaborativo (wikis, dropbox, google drive) & ,98 & 3 & 2,51 \\
\hline Ferramentas de manipulação de dados e gráficos (bases de dados pacotes estatísticos) & ,90 & 3 & 2,48 \\
\hline Softwares específicos de gestão acadêmica (Issura, UniMestre, giz, e-learning) & ,66 & 2 & 2,26 \\
\hline Tecnologia de simulação de jogos (primavera, simulação empresarial) & ,88 & 3 & 2,62 \\
\hline Uso de aplicativos de celular &, 21 & 6 & 2,13 \\
\hline
\end{tabular}

Fonte: Dados da pesquisa.

Com base nos resultados da Tabela 2, verificou-se que, de uma forma geral, existe uma discrepância dos níveis de aplicação das TICs entre os professores das IES da província de Manica. Os desvios padrões são elevados em todas as variáveis, em comparação à média - denotando que dentro da amostra existem professores que mais usam as TICs nos seus processos acadêmicos e outros que usam pouco. O estudo de Feldkercher e Mathias (2011) evidencia que a disponibilidade das tecnologias não garante que o professor as utilizará em benefício do desenvolvimento dos alunos. Assim sendo, a formação de professores para o uso das TICs deve favorecer o entendimento de que as mesmas podem proporcionar valiosas possibilidades de ensino, aprendizagem, pesquisa, promoção e divulgação de conhecimentos. 
A variável relacionada ao uso de aplicativos no celular foi a tecnologia que apresentou a maior média $(6,21)$ e um desvio padrão relativamente baixo em relação as outras variáveis $(2,13)$. Este resultado pode ser associado ao crescimento do mercado de telecomunicações móveis no país. Conforme Fernando (2016), entre 1997 a 2012, houve uma vertiginosa subida do número dos cadastros de telefonia móvel por 100 habitantes, de 0,013 para 29,08, enquanto o de usuários de telefonia fixa registou uma ligeira queda de 0,42 para 0,40 no mesmo período. A maior aderência à tecnologia móvel tem também a ver com a redução dos preços tanto de consumo e os acordos entre as operadoras de telefonia móvel, bem como a possibilidade de acesso à internet por esses dispositivos (Mabila, 2013).

A variável uso de softwares específicos de gestão acadêmica em Moçambique foi a que apresentou a média mais baixa na amostra estudada, denotando que os professores das IES públicas da província de Manica usam muito pouco essas tecnologias. Conforme Morais, Pombo, Batista, Moreira e Ramos (2014), o uso dessas TICs possibilita complementar o ensino presencial, facilitar a comunicação e o acesso a todo um conjunto de informações e conteúdo, podendo realizar quizzes, podcasts, e-portfolios, wikis, webquests, ligações externas, fóruns de discussão, questionários, avaliação, chats, referendos, diários, bases de dados, glossários, testes, workshops, textos, imagens, exercícios, apresentações, trabalhos de projeto e blogs, entre outras atividades acadêmicas. Ademais, softwares de gestão acadêmica são fundamentais para as instituições de ensino, na medida em que permitem o controle dos processos administrativos e da gestão acadêmica.

\subsection{Análise Fatorial e Logit: Fatores e suas Relações com as Tendências de Uso das TICs}

Em um primeiro momento, foram consideradas as 32 variáveis da terceira parte do questionário, tendo sido excluídas aquelas que contribuíram menos na criação dos fatores, ou seja, aquelas com cargas fatoriais e comunalidades menor do que 0,60, demonstrando que menos de $60 \%$ das variações dos construtos poderiam ser explicadas ou atribuídas a um dos fatores. Dessa forma, foram obtidos quatro fatores, compostos por 26 variáveis que representaram diferentes aspectos que influenciam a tendência de uso das TIC pelos professores das IES públicas da província de Manica. Para determinar a adequação da aplicação da análise fatorial para amostra estudada, recorreu-se ao teste Kaiser-Meyer-Olkin (KMO) juntamente com o teste de esfericidade Bartlett. Na Tabela 3 estão representados os resultados dos testes em referência.

Tabela 3: Testes de KMO e Bartlett.

\begin{tabular}{lll}
\hline Medida Kaiser-Meyer-Olkin de adequação de amostragem. & $\mathbf{0 , 9 2 1}$ \\
\hline Teste de esfericidade de Bartlett & Qui-quadrado aprox. & 2731,632 \\
& Df & 325 \\
& Sig. & $0,000^{(*)}$ \\
\hline
\end{tabular}

(*) Significância a 1\%. Fonte: Dados da pesquisa.

Os resultados indicaram a adequação da utilização da análise fatorial, tendo em conta que o teste KMO apresentou um valor próximo de 1 de $(0,921)$. O resultado do teste de esfericidade de Bartlett se mostrou significante a $1 \%$, permitindo rejeitar a hipótese nula da matriz das correlações ser uma identidade.

A etapa seguinte consistiu na determinação do número de fatores que representam o conjunto de variáveis que explicam a tendência de uso das TICs para os professores das IES públicas da província de Manica. Para tal, tomou-se como base o número de autovalores da matriz de correlação maiores do que 1 (Tabela 4). 
Tabela 4: Fatores formados e utilizados na pesquisa.

\begin{tabular}{llll}
\hline Fator & Total & \% da Variância & \% Acumulada \\
\hline 1 & 14,605 & 56,174 & 56,174 \\
2 & 2,287 & 8,796 & 64,969 \\
3 & 1,524 & 5,861 & 70,830 \\
4 & 1,067 & 4,103 & 74,933 \\
\hline
\end{tabular}

Fonte: Dados da pesquisa.

Pode-se perceber que após o ajustamento, foram criados quatro fatores que explicam 74,9\% da variância das variáveis incluídas no modelo para os fatores que explicam o contexto do uso das TICs na amostra.

Na nomeação dos fatores, o primeiro fator, expectativa de desempenho, está relacionado com as variáveis que dizem respeito aos ganhos esperados pela utilização das TICs, tendo uma correlação positiva com as seguintes variáveis: plano de utilização dos recursos tecnológicos na sala de aulas pelos professores da IES de Manica, recomendação das pessoas importantes para utilização das TIC, a pretensão de explorar no máximo os recursos tecnológicos em sala de aulas, a relevância do uso dos recursos tecnológicos em sala de aulas, a realização de tarefas com rapidez, a melhoria do desempenho dos professores, melhor controle do trabalho dos professores, melhoria de qualidade das aulas e uma clara interação com os estudantes.

O segundo fator, condições facilitadoras, está relacionado com a crença de existência de infraestrutura disponível para o funcionamento das TICs nas IES. Esse fator está positivamente correlacionado com as seguintes variáveis: suporte da direção das IES para utilização das TICs na sala de aulas, conhecimento suficiente para o uso das TICs, incentivo institucional para o uso das TICs, facilidade de resolução de problemas em caso de problemas das TICs e facilidade de aquisição de habilidade para utilização de recursos tecnológicos.

O terceiro fator, expectativa de esforço, diz respeito ao grau de facilidade para o uso das TICs na sala de aulas. Assim, esse fator tem uma relação negativa com as seguintes variáveis: dificuldade na condução das aulas pelo uso de recursos tecnológicos, redução da chance de os alunos obterem melhores resultados pelo uso das TICs e dificuldade de aprender a usar os recursos tecnológicos.

Finalmente, o quarto fator, influência social, está relacionado ao grau em que as outras pessoas acreditam que usando a tecnologia há melhorias nos processos educacionais. Portanto, esse fator está positivamente relacionado com as seguintes variáveis: o perfil dinâmico dos professores que usam as TICs nas IES de Manica, e maior prestígio dos professores que utilizam as TICs em relação aos que não usam. Na Tabela 5 estão apresentados os fatores e suas variáveis explicativas. 
Tabela 5: Variáveis que compõem os fatores e suas cargas explicativas.

\begin{tabular}{|c|c|c|}
\hline Fator & Variáveis que descrevem o fator & $\begin{array}{l}\text { Cargas } \\
\text { Fatoriais }\end{array}$ \\
\hline \multirow{12}{*}{$\begin{array}{l}\text { Expectativa de } \\
\text { desempenho }\end{array}$} & Eu planejo utilizar os recursos tecnológicos em minhas aulas nos próximos meses & $865 \quad 0$ \\
\hline & As pessoas que são importantes para mim acham que devo utilizar recursos tecnológicos nas minhas aulas & 745 \\
\hline & Pretendo explorar no máximo os recursos tecnológicos em sala de aulas & 864 \\
\hline & O uso de recursos tecnológicos e relevante em sala de aulas & 843 \\
\hline & Utilizar recursos tecnológicos em sala de aulas possibilita realizar as tarefas mais rapidamente & 775 \\
\hline & Eu pretendo utilizar os recursos tecnológicos em minhas salas de aulas nos próximos meses & 781 \\
\hline & O uso dos recursos tecnológicos melhora o meu desempenho (capacidade de pesquisa) & 851 \\
\hline & Usar recursos tecnológicos melhora a eficiência (economia de recursos, evita trabalho na minha IES) & 770 \\
\hline & $\begin{array}{l}\text { Usar recursos tecnológicos me possibilita um maior controle do meu trabalho (melhor controle e interação com meus } \\
\text { alunos }\end{array}$ & 774 \\
\hline & Eu irei utilizar os recursos tecnológicos em minhas aulas nos próximos meses & 769 \\
\hline & O uso de recursos tecnológicos auxiliou a melhoria da qualidade das minhas aulas & 692 \\
\hline & Minha interação com recursos tecnológicos é clara e compreensível & 716 \\
\hline \multirow{6}{*}{$\begin{array}{l}\text { Condições } \\
\text { Facilitadoras }\end{array}$} & A direção do curso tem me dado suporte para que eu utilize os recursos tecnológicos em sala de aulas & 768 \\
\hline & Eu tenho as condições necessárias para utilizar os recursos tecnológicos em minha sala de aulas & 793 \\
\hline & Eu tenho conhecimento suficiente para utilizar os recursos tecnológicos em minhas aulas & 665 \\
\hline & Em geral a instituição de ensino tem incentivado a utilização de recursos tecnológicos em sala de aulas & 707 \\
\hline & Quando há problemas de recursos tecnológicos que utilizo em sala de aulas é fácil resolver & 679 \\
\hline & Foi fácil adquirir a habilidade na utilização dos recursos tecnológicos nas aulas & 677 \\
\hline \multirow[t]{3}{*}{$\begin{array}{l}\text { Expectativa de } \\
\text { esforço }\end{array}$} & O uso de recursos tecnológicos torna mais difícil a condução das minhas aulas & 809 \\
\hline & O uso de tecnologia diminui a chance dos alunos obterem melhores resultados & 863 \\
\hline & Aprender a usar recursos tecnológicos é difícil para mim & 787 \\
\hline \multirow[t]{2}{*}{ Influência Social } & Os professores que usam os recursos tecnológicos na minha IES têm um perfil diferenciado (inovador e dinâmico) & 671 \\
\hline & $\begin{array}{l}\text { Os professores da minha instituição que usam os recursos tecnológicos em suas aulas têm maior prestígio do que } \\
\text { aqueles que não usam }\end{array}$ & 765 \\
\hline
\end{tabular}

Fonte: Dados da pesquisa.

Para analisar a confiabilidade das variáveis que compõem cada fator, recorreu-se a técnica do Alfa de Cronbach. Notou-se que três fatores tiveram valores de ${ }^{\alpha}$ de Cronbach superiores a 0,60, sendo: 0,972 para expectativa de desempenho, 0,912 para condições facilitadoras e 0,710 para influência social. Por outro lado, a expectativa de esforço é um constructo que apresenta um valor de ${ }^{\alpha}$ de Cronbach abaixo dos outros fatores $(0,427)$, denotando-se que as suas variáveis têm um fraco poder explicativo. Contudo, tendo em conta o contexto em que foi aplicada a pesquisa, considera-se que esse fator apresenta um valor razoável e atende às pressuposições teóricas (optando-se por mantê-lo). Por último, realizou-se a regressão logística, com intuito de determinar os fatores que mais se relacionam com a probabilidade de tendência de uso das TICs entre os professores da amostra. Na Tabela 6 estão apresentados os resultados dessa análise.

$\mathrm{Na}$ análise descritiva dos dados (painel A), verificou-se que a variável dummy (Tendência de uso de tecnologia) apresenta valores médios mais próximos de $0(0,20)$, o que quer dizer que existe uma menor tendência para o uso das TICs no meio dos respondentes, $20 \%$ apenas. Esta baixa tendência no uso das TICs pode ser justificada recorrendo-se ao estudo de 
Salimo e Gouveia (2017), ao argumentar que maior número de IES moçambicanas não tem acesso à Rede de Educação e Pesquisa (MORENET) e as IES que já se beneficiam têm problemas de acesso (interrupção sistemática, lentidão na transmissão, inoperacionalidades de serviços, e problemas técnicos de perda de sinal).

Um outro fator que pode ser associado a baixa tendência de uso das TICs no País, está relacionado aos altos preços de internet. Apesar de existir uma empresa que fornece a internet em banda larga e três empresas de telefonia móvel, os preços para aquisição de internet ainda são relativamente altos, contribuindo assim para a menor tendência de uso. Por outro lado, a falta de infraestruturas informáticas adequadas, fraco domínio e o fraco interesse de utilização das TICs entre os professores são fatores que concorrem negativamente na implementação das TICs na Educação em Moçambique (Mura \& Eduardo, 2020).

Tabela 6: Resultados da relação Fatores e tendência de uso das TICs.

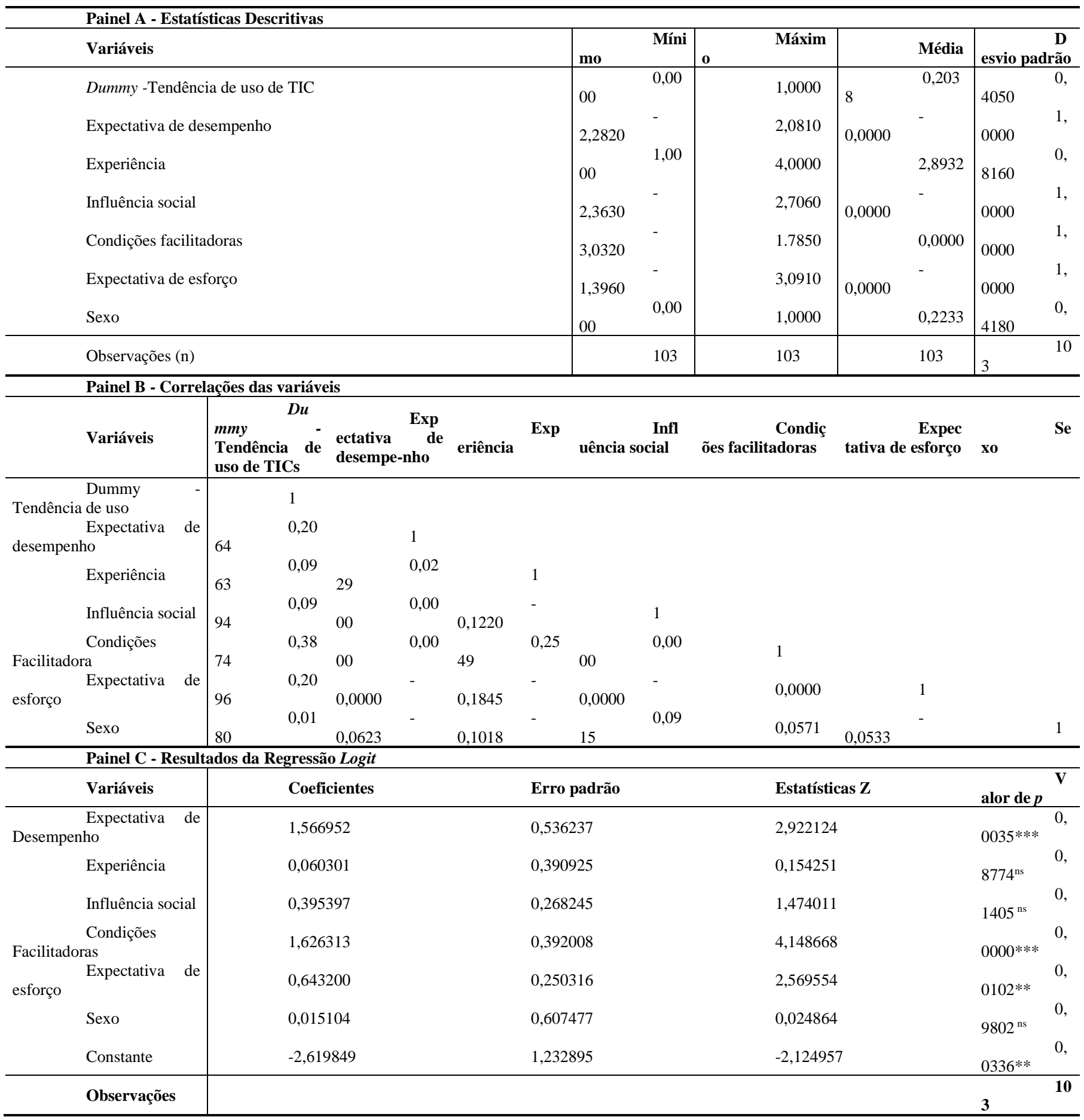


Legenda: ***Significância a $1 \%, * *$ Significativa a 5\% e *Significativo a 10\%; ns: não significativa. Fonte: Dados da pesquisa.

Quanto aos construtos expectativa de desempenho, influência social e condições facilitadores, os resultados indicaram para uma homogeneidade da amostra. A variável experiência apresentou valor mínimo de 1 e máximo 4, significando que os respondentes que fizeram parte da amostra têm experiência de até dois anos e os mais antigos estão na atividade docente há mais de 10 anos. Isso pode ser explicado pela própria história do surgimento das IES em Manica, que data do ano de 2006. Finalmente, verificou-se que a amostra tem mais homens do que mulheres, sendo elas representando apenas $22,33 \%$ dos docentes das IES analisadas.

Ainda, realizou-se a correlação das variáveis (Painel B). As variáveis apresentaram uma baixa correlação entre elas, principalmente as independentes, o que demonstra ausência de multicolinearidade - confirmada com os valores da Variance Inflation Factor (VIF) menores do que 10.

Com os resultados da Regressão Logit (Painel C), constatou-se a significância de três fatores determinantes do Modelo UTAUT, sendo expectativa de desempenho ( $\left.p=0,0035^{* * *}\right)$, condições facilitadoras $(p=0,0000 * * *)$, ambas significativas a $1 \%$, e expectativa de esforço $(p=0,0102 * *)$, significativa a $5 \%$, denotando associações positivas, ou seja, eles incentivam a probabilidade de os participantes da amostra serem mais tendentes ao uso de TICs.

Quanto ao construto expectativa de desempenho, os resultados desta pesquisa corroboram com os obtidos em outras desenvolvidas no campo de educação, ao indicarem a sua significância na aceitação e uso das TICs em ambientes de ensino (Abu-Al-Aish \& Love, 2013; Birch \& Irvine, 2009; Chao, 2019; Kaufmann, 2005a; Nganga, 2015; Pereira et al., 2013; Tacco, 2011). Por outro lado, resultados contrários foram encontrados nos estudos de Moraes, Cappellozza, e Meirelles (2014); Moreno e Silva (2009); e Reis, Pitassi, e Bouzada (2013), cujos resultados denotaram a ausência de relação entre a expectativa do desempenho com a intenção de uso das TICs.

Uma análise dos achados deste estudo sobre a expectativa de desempenho no contexto moçambicano permite inferir que os participantes da amostra têm maior probabilidade de usarem as TICs nos seus processos de ensino e aprendizagem porque eles acreditam que a sua utilização melhora o desempenho das tarefas acadêmicas. Para tanto, os participantes reconhecem a importância que as TICs desempenham na racionalização do tempo de preparação e organização do material para as aulas, na troca de informações entre docentes e estudantes, na melhoria da pesquisa, interação e dinâmica durante as aulas, rápido acesso as informações em tempo, bem como na melhoria de participação e desempenho dos estudantes. Esta percepção dos professores participantes da amostra pode ser justificada pelo fato do governo estar a implementar uma série de mecanismos que visem garantir a integração das TICs nos processos de ensino e aprendizagem conectando as diferentes IES por redes interconexão e Internet; criação de bibliotecas digitais; estabelecimento de uma plataforma de serviços compartilhados; projetos de financiamento de material informático, entre outras iniciativas.

No que diz respeito as condições facilitadoras, os resultados sugerem que as variáveis que compõem este constructo incentivam a probabilidade de os participantes da amostra terem maior tendência de usarem as TICs, quando eles percebem que existem nas IES condições adequadas em termos de infraestrutura e equipamentos para o uso das TICs. Outras pesquisas no campo de educação tiveram resultados similares ao demostrar que as condições facilitadoras têm influência positiva na aceitação e uso das TICs (Almeida \& Albertin, 2014; Birch \& Irvine, 2009; Faria et al., 2014; Kaufmann, 2005a; Meirelles \& Longo, 2015; Vargas; Silva, \& Rodriguez, 2019; Sasmito, 2018; Tacco, 2011). Por outro lado, resultados contrários aos achados nesta pesquisa foram encontrados na pesquisas de Birch e Irvine (2009); Nganga (2015); e de Reis et al.(2013) ao identificarem ausência de influência das condições facilitadoras na aceitação e uso das TICs.

A influência das condições facilitadoras no caso dos participantes da amostra pode ser justificada pelo fato das IES públicas moçambicanas terem beneficiado seus docentes com o acesso a equipamentos de informática, comunicação e 
laboratório para fins de ensino, pesquisa e administração, assim como a implantação da rede de interconexão de IES através de internet e a criação de bibliotecas digitais no âmbito dos projetos MORENET e Mozambique-Higher Education Project (projeto de ensino superior em Moçambique, aprovado em parceria com o Banco Mundial, em 2002, com objetivo de fortalecer as IES).

Quanto à expectativa de esforço, os professores que compuseram a amostra em estudo, acreditam que quanto mais simples e menos complexas forem as TICs, maior será a tendência do uso das Tecnologias de Informação e Comunicação, na medida em que elas se tornam mais fáceis de serem utilizadas. Resultados similares aos obtidos por estudo foram encontrados em outras pesquisas (Abu-Al-Aish \& Love ,2013; Birch \& Irvine, 2009; Chao, 2019; Faria et al., 2014; Henrique \& Faria, 2014; Kaufmann, 2005; Moraes et al., 2014; Nganga, 2015), ao constatar a significância da expectativa de esforço na aceitação e uso das TICs em diferentes campos de pesquisa.

Os achados desta pesquisa para o construto expectativa de esforço levam a inferir que os participantes da amostra tendem a usar mais as TICs por auxiliarem na condução dos seus processos letivos, melhorando a interação e a dinâmica das aulas. É importante salientar que, em consequência dos programas de formação de professores em matérias de promoção das TICs nas IES, eles podem ter desenvolvido habilidades necessárias usar essas ferramentas na realização das suas tarefas do dia a dia. A variável sexo, como de controle, não foi significativa.

De forma geral os achados desta pesquisa mostram consistência ao modelo de Venkatesh et al. (2003), quanto aos constructos expectativa de desempenho, condições facilitadoras e expectativa de esforço. Porém, a literatura mostra a existência pesquisas semelhantes e divergentes ao modelo, sendo importante considerar aspetos como cultura, contexto e situação econômica de cada país como elementos importantes para investigação futura.

Para o caso particular de Moçambique, que é o contexto desta pesquisa, os resultados mostraram menor tendência de uso das TICs na amostra pesquisada, revelando que ainda existem desafios referentes a infraestruturas para o funcionamento pleno das TICs, como é o caso da qualidade de internet, energia elétrica estável e serviço de telecomunicações que são elementos chaves para o uso eficiente das TICs. Contudo, não basta só disponibilizar todos os equipamentos e infraestrutura das TICs nas IES, é importante que sejam desencadeadas uma série de atividades de promoção das TICs assim como campanhas de mobilização e formação de professores para a sua integração nas aulas.

\section{Considerações Finais}

A facilidade que as TICs oferecem no processamento e apresentação de informações, assim como na construção de conhecimento no meio acadêmico, têm feito com que elas se tornem prioridade quando se discutem assuntos sobre políticas educacionais, principalmente no contexto atual em que o ensino remoto é incentivado por causa de medidas preventivas contra a pandemia causada pelo vírus SARS-CoV-2, a COVID-19. Contudo, a integração das TICs no contexto laboral do setor público ainda é um desafio, particularmente para as instituições públicas de países em desenvolvimento como é o caso de Moçambique.

A introdução das TICs nos processos de ensino e aprendizagem traz consigo uma série de mudanças na forma como é executado o trabalho docente, ou mesmo o papel por ele desempenhado, em que pode ser exigido a deixar de ser além de um instrutor para se tornar um facilitador do processo de ensino. Acontece que estas mudanças muitas das vezes não são aceitas com facilidade, havendo fatores que podem influenciar a aceitação ou rejeição na sua aplicação.

Assim, Venkatesh et al. (2003) elaboraram uma teoria considerando quatro fatores determinantes (a expectativa de performance, a expectativa de esforço para o uso, a influência social, e as condições facilitadoras) e quatro condições moderadoras (o gênero, a idade, a experiência e a voluntariedade do uso por parte do usuário) da aceitação e intenção de uso das Tecnologias da Informação e Comunicação pelos membros das organizações. 
No caso desta pesquisa foram analisadas, na percepção de 103 professores do ensino superior, as influências de fatores determinantes na tendência de utilização de Tecnologias da Informação e Comunicação na província de Manica, em Moçambique, baseando-se na adaptação do modelo UTAUT, de Venkatesh et al. (2003). Constatou-se que os fatores expectativa de desempenho, condições facilitadoras e expectativa de esforço apresentaram uma associação positiva para a probabilidade de tendência de uso das TICs entre os professores das IES públicas da província de Manica.

Quanto a tendência de uso das TICs, constatou-se que há uma menor tendência, podendo-se atribuir este resultado à existência de desafios em termos de criação de infraestruturas básicas para que as TICs adquiram condições de funcionar em plenitude. Isto é, verifica-se que existe uma baixa qualidade de internet e capacidade técnica para fazer a manutenção dos equipamentos existentes, assim como, a necessidade de uma maior integração entre os diferentes sectores da economia no âmbito de implementação da Política Informática

De forma geral os achados desta pesquisa mostram consistência ao modelo de (UTAUT, de Venkatesh et al. (2003),quanto aos constructos expectativa de desempenho, condições facilitadoras e expectativa de esforço. Porém a literatura mostra a existência pesquisas semelhantes e divergentes ao modelo, sendo importante considerar aspetos como cultura, contexto e situação econômica de cada país como elementos importantes para análise.

Os esforços envidados neste estudo geraram contribuições para os gestores das IES, no sentido de constituir em instrumento de apoio para identificação dos fatores que mais influenciam para tendência de uso das TICs em Manica, além de instrumentalizá-los com informações que podem contribuir para identificação de formas de melhorar a gestão de todo o processo de ensino e aprendizagem, bem como revelar quais elementos do modelo UTAUT podem ser visualizadas no contexto moçambicano, particularmente dos professores das IES de Manica . Assim, no intuito de ampliar os conhecimentos sobre essa área, sugere-se, para futuras pesquisas, a aplicação dos instrumentos de pesquisa aqui utilizados em outras províncias do país ou ainda em outros países africanos e com tecnologia em desenvolvimento. Ademais, há a sugestão de adicionar a temporalidade e alcance para o modelo UTAUT

\section{Agradecimentos}

Um agradecimento especial à Universidade Federal de Viçosa, ao Departamento de Administração e Contabilidade pela Oportunidade, à CAPES pela Concessão da bolsa e ao Instituto Superior Politécnico de Manica pelo apoio concedido.

\section{Referências}

Abu-Al-Aish, A., \& Love, S. (2013). Factors influencing students' acceptance of m-learning: An investigation in higher education. International Review of Research in Open and Distance Learning, 14(5), 82-107. https://doi.org/10.19173/irrodl.v14i5.1631

Ali, M. A., \& Abibo, T. (2018). Novas Tecnologias De Informação E Comunicação E Ensino Superior Em Moçambique: Integração Curricular E Desafios. Revista de Investigação Em Educação, 1-18.

Almeida, R., \& Albertin, A. L. (2014). Análise dos fatores determinantes da adoção de rede social corporativa com aplicaçãodo modelo utaut analysis of the determinants of adoption of corporate social network with application of utaut model. Revista Eletrônica Gestão e Serviços (Vol. 5).

Bento, A. R., \& Prus, É. M. (2011). A Tecnologia da Informação e Comunicação como Suporte no Ensino Aprendizagem de Alunos na Faculdade Privada The Technology of the Information and Communication as Support in the Teaching Learning of Students in Deprived University. In IV Simpósio Nacional de Tecnologia.

Bianchi, P., \& Hatje, M. (2007). a Formação Profissional Em Educação Física Permeada Pelas Tecnologias De Informação E Comunicação No Centro De Educação Física E Desportos Da Universidade Federal De Santa Maria. Pensar a Prática, 10(2), 291-306. https://doi.org/10.5216/rpp.v10i2.1097

Birch, A., \& Irvine, V. (2009). Preservice teachers' acceptance of ICT integration in the classroom: Applying the UTAUT model. Educational Media International, 46(4), 295-315. https://doi.org/10.1080/09523980903387506

Bobsin, D., Visentini, M. S., \& Rech, I. (2009). in Search of the State of the Art in Utaut: Extending the Considerations About the Use of Technology. Review of Administration and Innovation - RAI, 6(2), 99-118. https://doi.org/10.5585/rai.v6i2.275 
Castro, J. P. C. (2014). Aplicação do Modelo UTAUT na avaliação da aceitação de um sistema integrado de gestão na área de contabilidade de uma empresa de pequeno porte. LUME, Repositòrio Digital, 1-30. https://doi.org/10.1017/CBO9781107415324.004

Castro, J. P. C., Duarte, G. R., Momo, F. da S., Behr, A., \& Bonato Marcolin, C. (2020). Avaliação da Aceitação do ERP a partir do Modelo UTAUT. Management in Perspective, 1(2), 208-232. https://doi.org/10.14393/mip-v1n2-2020-47033

Chao, C. M. (2019). Factors determining the behavioral intention to use mobile learning: An application and extension of the UTAUT model. Frontiers in Psychology, 10(JULY). https://doi.org/10.3389/fpsyg.2019.01652

Correia, R. L., \& Santos, J. G. dos. (2013). A Importância da Tecnologia da Informação e Comunicação (TIC) na Educação a Distância (EAD) do Ensino Superior (IES). Revista Aprendizagem Em EAD, 2(1996), 1-16.

Cossa, E. F. R., Buque, V. L., \& Premugy, C. I. C. (2019). Desafios de Normação do Ensino Superior em Moçambique e suas Implicações na Qualidade de Ensino. FORGES, 1-11.

Faria, L. H. L., Giuliani, A. C., Pizzinatto, N. K., \& Pizzinatto, A. K. (2014). A Aplicabilidade do Modelo estendido ao consumo da Teoria Unificada da Aceitação e Uso de Tecnologia (UTAUT2) no Brasil: Uma avaliação do Modelo a partir de usuários de internet em smartphones. Revista de Administração Da UFSM, 7(2). https://doi.org/10.5902/1983465913088

Feldkercher, N., \& Mathias, C. V. (2011). Tecnologias da informação e comunicação aplicadas à educação superior presencial e a distância: o ponto de vista dos professores. Educação \& Tecnologia, 36-46.

Fernando, J. (2016). Os Desafios e Resultados das Formações nos Centros Provinciais de Recursos Digitais (CPRD) no âmbito do GovNet em Moçambique: O Caso do INTIC/CPRD-Nampula. Media Konservasi. UNIVERSIDADE EDUARDO MONDLANE http://dx.doi.org/10.1016/j.ecoenv.2017.03.002\%0Ahttp://www.fordamof.org/files/Sistem_Agroforestri_di_Kawasan_Karst_Kabupaten_Gunungkudul_Untuk _Pengelolaan_Telaga_Sebagai_Sumber_Air_Berkelanjutan.pdf\%0Ahttps://extension.msstate.edu/sites/default/files/pu

Garcia, Marta. Fernandes; Rabelo, Dirceu. da Silva; Do Amaral, S. F. (2012). Novas Competências Docentes Frente Às Tecnologias Digitais Interativas. Teoria e Prática Da Educação, 14(1), 79-87. https://doi.org/10.0000/rtpe.v14i1.16108

Gil, A. C. (2008). Métodos e Técnicas de pesquisa social (6a ed). Editora Atlas SA.

Ginger, L. J. (2017). A socio-technical Understanding of Information and Communication Technology (ICT) integration in Education - A case study of three Secondary schools in Mozambique. University of Kwazulu-natal.

Gonzales, I. P., Dos Santos, E. M., Rocha Silva, A. S., Santos de Miranda, M. A., Reis Oliveira, R. C., Marinho de Anias Daltro, E. F., \& Albuquerque, A. E. (2017). Teoria Unificada de Aceitação e Uso da Tecnologia: Revisão do UTAUT como Estrutura Conceitual em Eventos Científicos Brasileiros. Atas Da Conferencia Da Associacao Portuguesa de Sistemas de Informacao, 17(June 2017), 305-320. https://doi.org/10.18803/capsi.v17.305-320

Gonzales Jr, I., Santos, E., Silva, A., Miranda, M., Oliveira, R., Daltro, E., \& Albuquerque Jr, A. (2018). Teoria Unificada De Aceitação E Uso Da Tecnologia: Revisão Do Utaut Como Estrutura Conceitual Em Eventos Científicos Brasileiros, 305-320. https://doi.org/10.18803/capsi.v17.305-320

Henrique, L., \& Faria, L. (2014). A Aplicabilidade do Modelo Estendido ao Consumo da Teoria Unificada da Aceitação e Uso de Tecnologia (UTAUT2) no Brasil: Uma Avaliação do Modelo a Partir de Usuários de Internet em Smartphones. Revista de Administração Da Universidade Federal de Santa Maria, 7(2), $332-348$.

IFAD. (2018). Republic of Mozambique: Country strategic opportunities programme. Ifad-Eb 2018/123/R.4.

INE. (2019). Resultados definitivos IV REcenseamento Geral da População e Habitação. Maputo - Moçambique. www.ine.gov.mz

Kaufmann, S. M. A. (2005). Tecnologia da informação em uma instituição de ensino superior: Fatores que influenciam sua utilização, 115.

Mabila, F. (2013). Understanding what is happening in ICT in Mozambique. IResearchICTafrica.Net, 22(2-3), 11-22.

Maleane, S. O. T. (2012). Tecnologias de informação e comunicação como um meio de inclusão e exclusão social em Moçambique: o caso do ensino superior. Revista Ibero-Americana de Ciência da Informação. UNIVERSIDADE DE BRASÍLIA.

Marques, K. Z., Behr, A., \& Malanovicz, A. V. (2021). Avaliação da aceitação de um ERP no Departamento Contábil de uma Empresa Pública segundo o modelo UTAUT. Revista de Gestão, Finanças e Contabilidade, 10(1), 82-104. https://doi.org/10.18028/rgfc.v10i1.7232

Meirelles, F. de S., \& Longo, L. (2015). Adoção de plataforma estratégica de tecnologia de informação e comunicação: análise baseada no modelo UTAUT. Revista Da FAE, 17(1), 110-125.

Moraes, G. S., Cappellozza, A., \& Meirelles, F. S. (2014). A Tecnologia da Informação e as Manifestações Sociais: Um Estudo da Utilização das Redes Sociais para Participação nos Protestos. Encontro Da ANPAD - EnANPAD, 38, (June 2017), 1-16.

Morais, Carlos; Alves, Paulo; Miranda, L. (2013). Valorização dos Ambientes Virtuais de Aprendizagem por Professores do Ensino Superior. In Sistemas e Tecnologias de Informação, Atas da $8^{a}$ Conferência Ibérica de Sistemas e Tecnologias de Informação Lisboa, Portugal. Portugl.

Morais, N., Pombo, L., Batista, J., Moreira, A., \& Ramos, F. (2014). Uma Revisão de Literatura sobre o Uso das Tecnologias da Comunic ação no Ensino Superior. Prisma.Com, O(24), 162-185.

Moreno, V., \& Silva, J. M. B. (2009). Aplicação do Modelo UTAUT a Processos de Adoção de Sistemas ERP: Um Estudo Longitudinal. Anais Do Simpósio de Excelência Em Gestão e Tecnologia. 
Mura, S., \& Eduardo, F. (2020). E-Learning in the Process of Classroom Teaching and Learning: A Case Study at Catholic University of Mozambique Elearning no Processo de Ensino e Aprendizagem Presencial : Um Estudo de Caso na Universidade Católica de Moçambique Introdução. Revista Electrónica de Investigação e Desenvolvimento, 1(11), 1-16.

Nganga, C. S. N. (2015). Aceitação do uso de recursos tecnológicos pelos docentes de Pós-graduação em Contabilidade. Universidade Federal de Uberlândia.

Nunes Vargas, P., Maria Passos Da Silva, R., \& Daniel Menendez Rodriguez, T. (2019). A aceitação de um novo sistema em uma instituição federal de ensino pela perspectiva do modelo UTAUT. INPEAU/UFSC. https://repositorio.ufsc.br/handle/123456789/201772

Pereira, A. S., et al (2018). Metodologia da pesquisa científica. Universidade Federal de Santa Maria. http://repositorio.ufsm.br/handle/1/15824

Pereira, F. A. de M., Ramos, A. S. M., Nogueira, C. M. da S., Gomes, A. C. C., \& Mól, A. L. R. (2013). Intenção e padrão de uso do Moodle por alunos do EAD: uma abordagem da teoria unificada de aceitação e uso da tecnologia (UTAUT). Revista Brasileira de Administração Científica, 4(2), 158-170. https://doi.org/10.6008/ESS2179-684X.2013.002.0011

Raupp, Fabiano Maury; Beuren, I. M. (2006). Metodologia da pesquisa aplicável às ciências. In academia.edu. Retrieved from https://www.academia.edu/download/35790526/Cap_3_Como_Elaborar.pdf

Reis, Angislene Ribeiro Silva; Nobrega, Caio Talmag; Dantas, Diega Nogueira; Barroso, M. R. (2018). O Uso Das Tecnologias Da Informação E Comunicação Na Educação Profissional E Tecnologica. Educação e Tecnologia, 23(3), 1-14.

Reis, A. T. V. (2016). A importância das TICS e da Educação como processo comunicacional dialógico no ensino superior: Um Estudo da Universidade Estadual de Mato Grosso do Sul. http://tede.metodista.br/jspui/bitstream/tede/1557/2/Ana tereza Vendramini Reis final.pdf

Reis, P. N. C., Pitassi, C., \& Bouzada, M. A. (2013). Os fatores que explicam o grau de aceitação de um sistema de informação acadêmica: um estudo de caso com docentes de uma IES Privada. Revista Eletrônica de Sistemas de Informação, 12(3). https://doi.org/10.5329/resi.2013.1203002

Rosa, R. (2009). O potencial educativo das TICs no ensino superior: uma revisão sistemática, 121. http://www.uniube.br/biblioteca/novo/base/teses/BU000181088.pdf

Rosa, R., \& Cecílio, S. (2010). Educação e o uso Pedagógico das Tecnologias da Informação e Comunicação: A Produção do Conhecimento. Educ Foco, 15(I), 107-126.

Said-Hung, E. (2012). O uso das TIC por docentes de cenários de ensino superior na Colômbia. Convergencia, 19(58), 133-155.

Salimo, G., \& Gouveia, L. (2017). Contributos para o ensino superior em Moçambique: Os desafios da era digital. Proceedings CLME2017/VCEM $8^{\circ}$ Congresso Luso-Moçambicano de Engenharia / V Congresso de Engenharia de Moçambique, 1-16. https://paginas.fe.up.pt/clme/2017/Proceedings/data/papers/6953.pdf

Sasmito, V. A. (2018). Factors Influencing Social Commerce Adoption of Indonesian Immigrants in Taiwan: Applying the UTAUT Model. Retrieved from https://oatd.org/oatd/record?record=oai\%5C\%3ANSYSU\%5C\%3Aetd-0621118-134652

Silva, H., Dornelas, J., \& Araujo, M. (2020). Satisfação de professores com ferramentas para realização de aulas remotas durante a pandemia da COVID-19 SMEs Strategies View project B2B Relationship View project. In XXVII SIMPÓSIO DE ENGENHARIA DE PRODUÇÃO Economia Circular e Suas Interfaces Com A Engenharia De Produção (pp. 1-13). https://www.researchgate.net/publication/348443843

Tacco, F. M. de S. (2011). O impacto da influência social sobre a intenção de uso de sites de compras coletivas: um estudo baseado no modelo UTAUT.

Uamusse, A. A., Rosa Cossa, E. F., \& Kouleshova, T. (2020). Women participation in science, technology, engineering and mathematics courses in mozambican higher education. Revista Estudos Feministas, 28(1), 1-9. https://doi.org/10.1590/1806-9584-2020V28N168325

Venkatesh, V., Morris, M. G., Davis, G. B., \& Davis, F. D. (2003). User acceptance of information technology: Toward a unified view. MIS Quarterly: Management Information Systems, 27(3), 425-478. https://doi.org/10.2307/30036540 